\title{
Evaluation of oxidative stress indices after exposure to malathion and protective effects of ascorbic acid in ovarian tissue of adult female rats
}

Somayyeh Abbasabad Arab ${ }^{1}$, Mohammad Reza Nikravesh ${ }^{2}$, Mahdi Jalali², AliReza Fazel $^{3}$

${ }^{1}$ M.Sc. Student of Anatomy, Department of Anatomy and Cell Biology, School of Medicine, Mashhad University of Medical Sciences, Mashhad, Iran

${ }^{2}$ Ph.D. of Anatomy, Professor, Department of Anatomy and Cell Biology, School of Medicine, Mashhad University of Medical Sciences, Mashhad, Iran

${ }^{3}$ Ph.D. of Anatomy, Professor, Microanatomy Research Center, Mashhad University of Medical Sciences, Mashhad, Iran

Type of article: Original

\begin{abstract}
Background: Malathion is one of organophosphate pesticides that is extensively used in farming and crops to control pests. Malathion induces oxidative stress in the various tissues such as the reproductive system.

Objective: To determine the effects of malathion on malondialdehyde (MDA) level and glutathione (GSH) content in female rat ovary tissue as well as to assess the protective role of Ascorbic Acid.

Methods: This study was carried out at the Department of Anatomy and Cell Biology (School of Medicine, Mashhad University of Medical Sciences, Mashhad, Iran) in 2015. In this experimental study, 30 adult, female, Wistar rats (weight range: 200-250 g) were divided into five groups, each group consisting of six rats: control group (no interventions), sham group (normal saline $0.9 \% 50 \mathrm{mg} / \mathrm{kg}$ ), experimental group 1 (Ascorbic Acid 200 $\mathrm{mg} / \mathrm{kg}$ ), experimental group 2 (malathion $50 \mathrm{mg} / \mathrm{kg}$ ), and experimental group 3 (malathion $50 \mathrm{mg} / \mathrm{kg}+$ Ascorbic Acid $200 \mathrm{mg} / \mathrm{kg}$ ). Malathion, solvents and Ascorbic Acid were injected intraperitoneally. After two weeks, the animals were anaesthetized with intraperitoneal ketamine/xylazine (60 and $6 \mathrm{mg} / \mathrm{kg}$, respectively) and then scarified, and the right ovarian was used to measure levels of MDA, a marker of lipid peroxidation, and GSH content. Data were analyzed by SPSS version 16, using descriptive statistics, One Way ANOVA, and TukeyKramer test. A p-value $<0.05$ was set as significance level.

Results: This study has shown that malathion increased MDA level and reduced GSH content compared with the control group $(\mathrm{p}<0.001)$. Also, administration of malathion in combination with Ascorbic Acid, reduced MDA level and increased the GSH content in rat ovarian tissue.

Conclusion: Malathion induced lipid peroxidation and Oxidative stress in the ovarian of Rats. In addition, it appears that Ascorbic Acid, due to its antioxidant, can recover malathion-induced poisonous changes.

Keywords: Malathion, Malondialdehyde, Ascorbic Acid, Ovary, Rats
\end{abstract}

\section{Introduction}

Malathion (diethyl methoxy thio-phosphoryl thio-succinate) is a chemical pesticide organophosphate family, which is widely used in industry, agriculture, veterinary medicine, and the medical sector to control insects on crops, produce ornamental plants, grasses, fruits, vegetables, and anti-parasitic drugs for disease vector control in many countries $(1,2)$. Despite this, malathion has less toxic insecticide than parathion but with the excessive use of malathion in developing countries, especially in agriculture, it has been reported as the third cause of poisoning and death, especially in Iran (3). These pesticides are absorbed through the skin and mucous membranes (4) and affect various organs of the body including the liver, kidneys, pancreas, testis, etc. Malathion in the body, during oxidation-reduction reactions, is converted into a metabolite called malaoxon, the main role of which is to cause

\section{Corresponding author:}

Professor Dr. Mohammad Reza Nikravesh, Department of Anatomy and Cell Biology, School of Medicine, Mashhad University of Medical Sciences, Mashhad, Iran.

Tel.: +98.9153114419, Fax: +98.5138002484, Email: Nikraveshmr@mums.ac.ir

Received: November 25, 2017, Accepted: February 26, 2018, Published: May 2018

iThenticate screening: February 17, 2017, English editing: Match 07, 2018, Quality control: April 12, 2018

This article has been reviewed / commented by four experts

(C) 2018 The Authors. This is an open access article under the terms of the Creative Commons Attribution-NonCommercialNoDerivs License, which permits use and distribution in any medium, provided the original work is properly cited, the use is non-commercial and no modifications or adaptations are made. 
toxicity in mammals, insects and plants so that malaoxon toxicity is 40 times more than that of malathion (5). The main mechanism of the organophosphates (especially parathion, malathion) is alteration of neurotransmitters in insects nervous system. Different mechanisms of organophosphate toxicity have been proposed, including the inhibition of acetylcholinesterase, which lead to the accumulation of acetylcholine and cholinergic activity in muscarinic and nicotine receptors. However, many effects of these compounds are not associated with the inhibition of acetylcholinesterase (6). Oxidative stress is another mechanism affecting the toxicity of organophosphate pesticides, which leads to the production of free radicals such as reactive oxygen species (ROS) and lipid peroxidation of cell membranes (7). Also, followed by changes in the antioxidant defense mechanisms in the body. Under normal conditions, there is a balance between the production and elimination of free radicals. Imbalance in this process leads to oxidative stress and multiple pathological changes in cellular macromolecules such as nucleic acid (DNA), lipids, carbohydrates, proteins and enzymes $(8,9)$. The thiol groups, at a concentration of about 5 millimolar (mM) in animal cells (10), are evaluated as an indicator of oxidative stress which is capable of sweeping free radicals. GSH is one of the thiol groups as well as an essential component of the normal immune system, and plays an essential role in protecting body cells from damages caused by peroxidase hydrogen and oxygen species $(11,12)$. The severity of oxidative damage can be measured by estimating aldehyde products of lipid peroxidation such as MDA. The oxidation of unsaturated fatty acids leads to the production of MDA (11, 13). These aldehydes can covalently bind to proteins and other molecules through reacting with thiol groups and alter biological macromolecules function. Antioxidants are compounds that prevent excessive production of free radicals and damage caused by them $(14,15)$. Antioxidants exist in two enzymatic and non-enzymatic forms (10). Ascorbic Acid, a non-enzymatic antioxidant, has a low molecular weight and is soluble in water, which reduces lipid peroxidation and production of oxidative stress leads to the prevention of many harmful effects (16, 17). Considering the above mentioned, for the first time, we determined glutathione content and MDA levels in $50 \mathrm{mg} / \mathrm{kg}$ malathion-induced ovarian tissues in adult female Wistar Rats and evaluated the protective effects of Ascorbic Acid.

\section{Material and Methods}

\subsection{Animals and treatment}

In this experimental study, 30 adult female Wistar rats (two-month-old), with a weight range of 200-250 g (18), were randomly divided into five groups, each group consisting of 6 rats $(14,15)$ : control group (no interventions), sham group (normal saline 0.9\% $50 \mathrm{mg} / \mathrm{kg}$ ), experimental group 1 (Ascorbic Acid $200 \mathrm{mg} / \mathrm{kg}$ ) (17, 19, 20), experimental group 2 (malathion $50 \mathrm{mg} / \mathrm{kg}$ ), and experimental group 3 (malathion $50 \mathrm{mg} / \mathrm{kg}+$ Ascorbic Acid 200 $\mathrm{mg} / \mathrm{kg}$ ) (Table 1). In this study, malathion, solvent (normal saline) and Ascorbic Acid were injected intraperitoneally $(21,22)$. After 2 weeks (16), rats were anaesthetized with intraperitoneal ketamine/xylazine $(60 \mathrm{mg} / \mathrm{kg} \mathrm{and} 6 \mathrm{mg} / \mathrm{kg}$, respectively). Then, animals were scarified, and the right ovarian were used to measure the levels of MDA and GSH content. These Rats were kept in standard conditions (temperature $2 \pm 22{ }^{\circ} \mathrm{C}$ and a 12 -hour light/dark cycle) and had free access to food and water throughout the experiment. Also, the study was not blind.

Table 1. Mean \pm SD of GSH, MDA and compare them with different groups

\begin{tabular}{|l|l|l|}
\hline Treatments & Glutathione & Malondialdehyde $^{*}$ \\
\hline Control & $4783.861 \pm 210.23$ & $110.04 \pm 10.07$ \\
\hline Sham (Normal saline $50 \mathrm{mg} / \mathrm{kg})$ & $4711.593 \pm 453.45$ & $107.91 \pm 12.09$ \\
\hline Exp 1 (Ascorbic Acid $200 \mathrm{mg} / \mathrm{kg})$ & $4720.748 \pm 490.68$ & $98.63 \pm 4.80$ \\
\hline Exp 2 (Malathion $50 \mathrm{mg} / \mathrm{kg}$ ) & $1465.815 \pm 391.76$ & $173.02 \pm 4.16$ \\
\hline Exp 3 (Malathion $50 \mathrm{mg} / \mathrm{kg}+$ Ascorbic Acid $200 \mathrm{mg} / \mathrm{kg}$ ) & $2737.043 \pm 198.83$ & $141.13 \pm 12.41$ \\
\hline
\end{tabular}

* In experimental groups 2 and 3, glutation and Malondialdehyde level indicated significant difference among other groups

\subsection{Ethics}

All the experimental protocols were approved by the Ethical Committee of Mashhad University of Medical Sciences (IR.MUMS.REC.1393.151) and this experiment was conducted at the Department of Anatomy and Cell Biology, School of Medicine, Mashhad University of Medical Sciences, in 2015.

\subsection{Chemicals}

In this study, technical malathion 99\% was purchased from Ariashimi Company, and the stock solution with a concentration of $50 \mathrm{mg} / \mathrm{ml}$ was freshly prepared in normal saline $0.9 \%$. TBA (thiobarbituric acid), DTNB [5, 5 dithiobis-(2-nitrobenzoic acid)], KCL (potassium chloride), phosphoric acid, TCA (trichloroacetic acid), n-butanol were purchased from Merck company (Germany). Ascorbic Acid and reduced GSH were obtained from SigmaAldrich (St. Louis, Missouri, USA). All other chemicals used in this study were of the highest purity available and purchased from Sigma-Aldrich (Germany). 


\subsection{Measurement of malondialdehyde (MDA) levels in the ovarian tissue}

At the end of the study period ( 2 weeks), the ovarian tissues were removed and washed in normal saline. MDA levels were determined according to the method of Fernandez et al. (23). Briefly, lipid peroxidation content was investigated by measuring the levels of MDA, an important marker of oxidative stress, in the ovarian tissue of Rats. Ovarian tissues of different groups were homogenized for $2 \mathrm{~min}$ at $4^{\circ} \mathrm{C}$ (POLYTRON-PT 10-35, Kinematica, Switzerland) in $1.15 \% \mathrm{KCl}$ in order to provide a $10 \%$ homogenate. Then, $3 \mathrm{ml}$ phosphoric acid (1\%) and $1 \mathrm{ml} \mathrm{TBA}$ $(6 \%)$ were added to $10 \%$ tissue homogenates in the potassium chloride (KCL) and then the mixture was heated in a boiling water bath for 45 minutes which MDA reacts with thiobarbituric acid (TBA) and creates a pink complex with maximum absorbance at $532 \mathrm{~nm}$. After cooling the mixture, $4 \mathrm{ml}$ of $\mathrm{n}$-butanol was added and was vertexed for 1 minute and was centrifuged for 20 minutes (3000 RPM). The high pink colored fluid was transferred to a test tube and the absorbance was read at $532 \mathrm{~nm}$ using a spectrometer. The calibration curve is designed using Tetrabutylammonium MDA. The MDA level was expressed as nmol/g of tissue (nmol/g tissue).

\subsection{Measurement of glutathione (GSH) content in the ovarian tissue}

The content of GSH in the ovarian tissue was investigated using the method of Moron et al. (24). Briefly, the task's basis is the formation of yellow color following the addition of 5,5'dithiobis-(2-nitrobenzoic acid) (DTNB) to the compound containing sulfhydryl groups. To do this, $1300 \mu \mathrm{l}$ of the homogenated tissue was mixed and vertexed with $300 \mu \mathrm{l}$ of Trichloroacetic acid 10\% (TCA). The upper layers were removed after centrifugation at $2500 \mathrm{RPM}$ for 10 minutes and was mixed with the reaction mixture containing $2 \mathrm{ml}$ phosphate buffer (PH: 8) and $500 \mu \mathrm{l}$ of DTNB. At the time of 10 minutes, the absorption at a wavelength of $412 \mathrm{~nm}$ was read using a spectrophotometer (Jenway 6105 UV/VIS, UK). At the end, the amount of GSH standard generated curve was determined using commercially available GSH. The GSH content was expressed as $\mathrm{nmol} / \mathrm{g}$ tissue (nmol/g tissue).

\subsection{Statistical analysis}

In this study, data were analyzed using SPSS software (version 16). Results are expressed as mean \pm SD. Statistical analysis was performed using One Way ANOVA and Tukey-Kramer test in order to compare the mean differences between the groups, and the difference was considered statistically significant at $\mathrm{p}<0.05$.

\section{Results}

\subsection{The effect of Ascorbic Acid on malondialdehyde (MDA) level of rats treated with malathion}

As shown in Table 1, there was a significant increase in MDA levels in experimental group 2 (malathion) and experimental group 3 (malathion + Ascorbic Acid), compared to the control group $(\mathrm{p}<0.001)$. In addition, the level of MDA in experimental group 2 (malathion) was significantly increased compared with experimental group 3 (malathion + Ascorbic Acid) $(\mathrm{p}<0.001)$. However, the level of MDA in the control, sham and Ascorbic Acid groups was not significantly different (Figure 1). None of the rats died during the experiment.

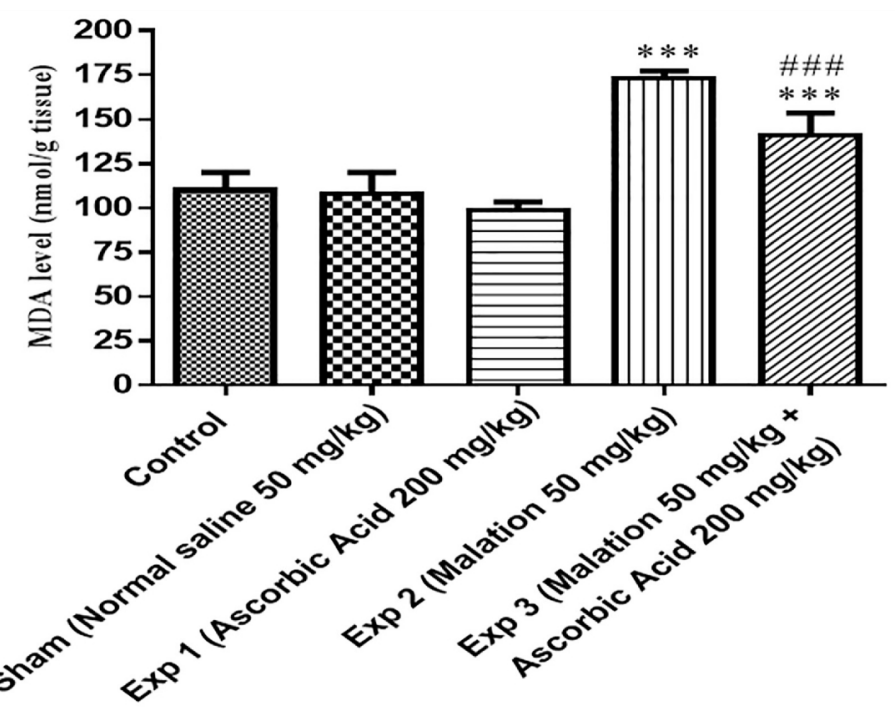

Data are shown as mean $\pm \mathrm{SD}$, One-way ANOVA and Tukey-Kramer. $* * * \mathrm{P}<0.001$, compared to the control group, and \#\#\#P< 0.001 , compared to the malathion $50 \mathrm{mg} / \mathrm{kg}$ group, $\mathrm{MDA}=$ malondialdehyde, Exp $=$ experimental, $\mathrm{n}=6$.

Figure 1. Effects of malathion $50 \mathrm{mg} / \mathrm{kg}$ subacute treatment on the malondialdehyde (MDA) of ovary female rats. Malathion, normal saline, and Ascorbic Acid were administered intraperitoneally, once a day and for 2 weeks, respectively. 


\subsection{The effect of Ascorbic Acid on glutathione (GSH) content of rats treated with malathion}

As shown in Table 1, there was a significant decrease in GSH content in experimental group 2 (malathion) and experimental group 3 (malathion + Ascorbic Acid), compared to the control group $(p<0.001)$. In addition, the content of GSH in experimental group 2 (malathion) was significantly decreased compared with experimental group 3 (malathion + Ascorbic Acid) $(\mathrm{p}<0.001)$. However, the content of GSH in the control, sham and Ascorbic Acid groups was not significantly different (Figure 2). None of the rats died during the experiment.

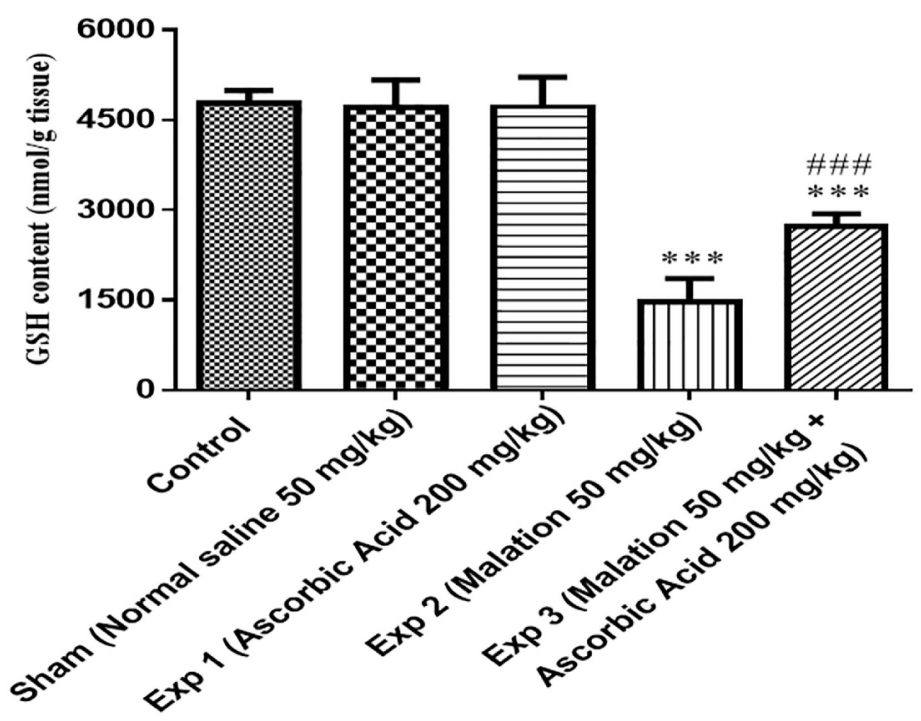

Data are shown as mean $\pm \mathrm{SD}$, One-way ANOVA and Tukey-Kramer. ${ }^{* * *} \mathrm{p}<0.001$, compared to the control group, and $\# \# \#$ p $<0.001$, compared to the malathion $50 \mathrm{mg} / \mathrm{kg}$ group, $\mathrm{GSH}=$ glutathione, Exp = experimental, $\mathrm{n}=6$.

Figure 2. Effects of malathion $50 \mathrm{mg} / \mathrm{kg}$ subacute treatment on the glutathione (GSH) of the ovary of female rats. Malathion, normal saline, and Ascorbic Acid were administered intraperitoneally, once a day and for 2 weeks, respectively.

\section{Discussion}

In this study, the level of MDA and glutathione content were investigated in ovarian tissue in female rats, caused by malathion. Also, Ascorbic Acid was used as a preservative. Based on the findings, experimental group 1, which only received malathion, experienced a significant increase in the level of MDA, compared to the control group $(\mathrm{P}<0.001)$. However, in experimental group 2, the co-administration of Ascorbic Acid and malathion reduced the level of MDA compared with experimental group $1(\mathrm{p}<0.001)$. Also, the glutathione content in experimental group 1 was significantly decreased compared with the control group $(\mathrm{p}<0.001)$. In addition, the group of malathion along with Ascorbic Acid led to increase in the content of GSH in the experimental group $2(p<0.001)$. Organophosphates exposure is associated with adverse human and animal health effects such as the reproductive system (25). Previous studies have proven that organophosphate can cause changes in the biochemistry and histopathology of different organs $(26,27)$. The ovary is one of the target organs, which plays an important role in reproductive system function through producing oocytes and hormones (28). The oxidative stress plays a main role in pathogenesis of various diseases such as cancer, diabetes, atherosclerosis, and lung disease and the reproductive system by means of free radicals $(17,25)$. Various studies have shown that organophosphates pesticides have numerous effects on the testicles of mammals. However, there are few studies done regarding their effects on the ovary (29). According to several previous studies, organophosphate increased levels of MDA as a marker of oxidative stress in various tissues (e.g., heart, lung, liver, and brain tissues) (7,30). Malathion changes the antioxidant system of the cell and increases the peroxidation of the lipid membrane, resulting in increased level of MDA in ovarian tissues of rats $(31,32)$. A study found that the size of ovarian tissue reduced, and MDA level increased when exposed to endosulfan and malathion in low $(11 \mathrm{mg} / \mathrm{kg})$ and high $(33 \mathrm{mg} / \mathrm{kg})$ doses in adult Wistar Albino rats (33). Another study has proven that oocytes of fetal ovaries exposed to $250 \mu \mathrm{M}$ of malathion, leads to a significant decrease in oocytes' survival and changes the expression of genes encoding proteins in oocytes after $24 \mathrm{~h}$ exposure (29). Another study revealed that toxic effects of diazinon and malathion on the reproductive system leads to impairment oocyte viability, fertilization, reduces healthy follicles and increases the number of atretic follicles by increasing the active oxygen species and MDA levels in ovarian female rats and porcine $(25,34)$. Also, chronic diazinon exposure increases lipid peroxidation levels, and reactive oxygen species production leads to increased MDA levels and reduced GSH 
content in testis tissue male Wistar Albino rats (35). It has been demonstrated that organophosphate pesticide significantly decreases glutathione content in various tissues of rats $(36,37)$. A study has proven that the chlorpyrifos, an organophosphate pesticide, reduced sperm number and increased stopped spermatogenesis in testicular tissue Wistar rats (38). Diazinon, fenthion and malathion increased changes in DNA and binding protein in the HepG2 cells (39), ovarian, erythrocytes and testis tissue through increased oxidative stress and levels of MDA and decreased glutathione content $(30,40)$. In this study, we found that content of glutathione reduced and MDA level increased in ovary tissue of female rats. According to previous studies, it demonstrated that the probable damage to these effects is less for humans due to the amount of exposure to organophosphate pesticide is very important. Therefore, further studies should be done on generalizing it to humans (25). In such circumstances, to avoid exposure and prevent the side effects of organophosphorus pesticides, it is recommended to use a suitable antioxidant such as Ascorbic Acid. Ascorbic Acid is available in numerous foods and can easily intake an antitoxic effect by daily consumption. Ascorbic Acid is a water-soluble vitamin, which can decline the amount of free radicals through its antioxidant properties (41). Previous studies confirmed that Vitamin C reduced MDA levels and lipid peroxidation, and increased glutathione content in rat kidney (42). Also, simultaneous use of vitamin $\mathrm{E}$ and $\mathrm{C}$ will significantly contribute to the improvement of lipid peroxidation and oxidative stress induced by diazinon in heart (43), erythrocytes and brain tissues $(44,45)$. Also, another study reported that methyl parathion induced hepatotoxicity is prevented by Ascorbic Acid and vitamin E (46). In addition, Uzun et al. showed that the malathion induced side effect is prevented by Ascorbic Acid in rat testis (21). Therefore, the studies are consistent with the results of the present study which can use Ascorbic Acid as an antioxidant and will improve the oxidative stress. This study was limited by assessment of apoptotic effect, the other antioxidant parameters such as Nrf-2 and oocytes quality in exposure to malathion. For this reason, it was necessary to carry out superior studies on large sample size to evaluate these factors.

\section{Conclusions}

According to the results obtained in this study, it can be concluded that the oxidative stress in rats treated with malathion causes cell toxicity. Also, considering the biochemical effects of malathion in ovary rats (reducing GSH content and increasing levels of MDA), there is the risk of cytotoxicity in agriculturalists and other people who are in contact with these materials. Therefore, there is a critical need to treat and inhibit the entry of pesticides into the body, prevent tissue damage under the influence of these pesticides and stop other disorders such as dysfunction of the gonads and the risk of infertility. Thus, the use of Ascorbic Acid as an antioxidant in this study can protect the ovary tissue against this toxicity by reducing the MDA level and increasing GSH content.

\section{Acknowledgments:}

The current article is a part of the descriptive science thesis in M.Sc. which is conducted based on research funding (922 842) in Mashhad University of Medical Sciences. Therefore, we would hereby like to extend our appreciation to the Vice Chancellor for Research of this university as well as Mrs. Tajadod, a histochemistry laboratory expert at Mashhad University of Medical Sciences for her sincere assistance and technical services as well as the toxicology section of the School of Pharmacy.

\section{Conflict of Interest:}

There is no conflict of interest to be declared.

\section{Authors' contributions:}

All authors contributed to this project and article equally. All authors read and approved the final manuscript.

\section{References:}

1) Dorri SA, Hosseinzadeh H, Abnous K, Hasani FV, Robati RY, Razavi BM. Involvement of brain-derived neurotrophic factor (BDNF) on malathion induced depressive-like behavior in subacute exposure and protective effects of crocin. Iran J Basic Med Sci. 2015; 18(10): 958-66. PMID: 26730329, PMCID: PMC4686579.

2) Hoffmann U, Papendorf T. Organophosphate poisonings with parathion and dimethoate. Intensive Care Med. 2006; 32(3): 464-8. doi: 10.1007/s00134-005-0051-z.

3) Abdolmaleki M, Ghasemi H, Heidarishayesteh T, Hosseinizaijood M, Ranjbar A. Assessing the protective effects of zinc on oxidative injury biomarkers in acute malathion induction in male rats. Journa OF Ilam University OF Medical Sciences. 2014; 22: 147-52. 
4) Sarabia L, Maurer I, Bustos-Obregon E. Melatonin prevents damage elicited by the organophosphorous pesticide diazinon on the mouse testis. Ecotoxicol Environ Saf. 2009; 72(3): 938-42 doi: 10.1016/j.ecoenv.2008.04.022.

5) Wankhade VW. Effect of Malathion on Lipid Peroxidation and Enzymatic Activity of Liver Serum and Brain at Different Exposure Periods in Mice. RJET. 2012; 6(4): 142. doi: 10.3923/rjet.2012.142.150.

6) Storm JE, Rozman KK, Doull J. Occupational exposure limits for 30 organophosphate pesticides based on inhibition of red blood cell acetylcholinesterase. Toxicology. 2000; 150(1-3): 1-29. doi: 10.1016/S0300483X(00)00219-5.

7) El-Demerdash FM. Lipid peroxidation, oxidative stress and acetylcholinesterase in rat brain exposed to organophosphate and pyrethroid insecticides. Food Chem Toxicol. 2011; 49(6): 1346-52. doi: 10.1016/j.fct.2011.03.018.

8) Buyukokuroglu ME, Cemek M, Yurumez Y, Yavuz Y, Aslan A. Antioxidative role of melatonin in organophosphate toxicity in rats. Cell Biol Toxicol. 2008; 24(2): 151-8. doi: 10.1007/s10565-007-9024-Z.

9) Milatovic D, Gupta RC, Aschner M. Anticholinesterase toxicity and oxidative stress. The Scientific World Journal. 2006; 6: 295-310. doi: 10.1100/tsw.2006.38

10) Couto N, Malys N, Gaskell SJ, Barber J. Partition and turnover of glutathione reductase from Saccharomyces cerevisiae: a proteomic approach. J Proteome Res. 2013; 12(6): 2885-94. doi: $10.1021 / \mathrm{pr} 4001948$.

11) Salehi B, Vakilian K, Ranjbar A. Relationship of Schizophrenia with Lipid Peroxidation, Total Serum Antioxidant Capacity and Thiol Groups. IJPCP. 2008; 14(2): 140-5.

12) Kayhan FE. Biochemical evidence of free radical-induced lipid peroxidation for chronic toxicity of endosulfan and malathion in liver, kidney and gonadal tissues of wistar albino rats. Fresen Environ Bull. 2008; 17: 1340-3.

13) Hosseinzadeh Kolagar A, Bidmeshkipour A, Gholinezhad Chari M. Total Antioxidant Capacity and Malondialdehyde Levels in Seminal Plasma Among The Varicocele-Suffering Men. JIUMS. 2009; 17(2): 15-23.

14) Kalender S, Uzun FG, Durak D, Demir F, Kalender Y. Malathion-induced hepatotoxicity in rats: the effects of vitamins C and E. Food Chem Toxicol. 2010; 48(2): 633-8. doi: 10.1016/j.fct.2009.11.044.

15) Ramanathan K, Balakumar B, Panneerselvam C. Effects of ascorbic acid and a-tocopherol on arsenicinduced oxidative stress. Hum Exp Toxicol. 2002; 21(12): 675-80. doi: 10.1191/0960327102ht307oa.

16) Sargazi Z, Nikravesh MR, Jalali M, Sadeghnia H, Anbarkeh FR, Mohammadzadeh L. Gender-related differences in sensitivity to diazinon in gonads of adult rats and the protective effect of vitamin E. IJWHR Sci. 2015; 3: 40-7. doi: 10.15296/ijwhr.2015.07.

17) Possamai FP, Fortunato JJ, Feier G, Agostinho FR, Quevedo J, Wilhelm Filho D, et al. Oxidative stress after acute and sub-chronic malathion intoxication in Wistar rats. Environ Toxicol Pharmacol. 2007; 23(2): 198-204. doi: 10.1016/j.etap.2006.09.003.

18) Ozsoy A, Nursal A, Karsli M, Uysal M, Alici O, Butun I, et al. Protective effect of intravenous lipid emulsion treatment on malathion-induced ovarian toxicity in female rats. 2016; 20(11): 2425-34.

19) Fortunato JJ, Agostinho FR, Reus GZ, Petronilho FC, Dal-Pizzol F, Quevedo J. Lipid peroxidative damage on malathion exposure in rats. Neurotox Res. 2006; 9(1): 23-8. doi: 10.1007/BF03033304.

20) Choudhary N, Goyal R, Joshi SC. Effect of malathion on reproductive system of male rats. J Environ Biol. 2008; 29(2): 259-62. PMID: 18831386.

21) Uzun FG, Kalender S, Durak D, Demir F, Kalender Y. Malathion-induced testicular toxicity in male rats and the protective effect of vitamins $\mathrm{C}$ and E. Food Chem Toxicol. 2009; 47(8): 1903-8. doi: 10.1016/j.fct.2009.05.001.

22) Uzunhisarcikli M, Kalender Y, Dirican K, Kalender S, Ogutcu A, Buyukkomurcu F. Acute, subacute and subchronic administration of methyl parathion-induced testicular damage in male rats and protective role of vitamins C and E. Pestic Biochem Physiol. 2007; 87(2): 115-22. doi: 10.1016/j.pestbp.2006.06.010.

23) Fernández J, Pérez-Álvarez JA, Fernández-López JA. Thiobarbituric acid test for monitoring lipid oxidation in meat. Food Chem Toxicol. 1997; 59(3): 345-53. doi: 10.1016/S0308-8146(96)00114-8.

24) Moron MS, Depierre JW, Mannervik B. Levels of glutathione, glutathione reductase and glutathione Stransferase activities in rat lung and liver. Biochim Biophys Acta. 1979; 582(1): 67-78. doi: 10.1016/03044165(79)90289-7.

25) Rahmanian E, Tavakol KE, Kargar L. The Effect of Herbicide Paraquat and Organophosphate Pesticide Malathion on Changes of Sex Hormones in Female Rats. Biomed Pharmacol J. 2015; 8(2). doi: $10.13005 / \mathrm{bpj} / 851$. 
26) Gomes J, Dawodu AH, Lloyd O, Revitt DM, Anilal SV. Hepatic injury and disturbed amino acid metabolism in mice following prolonged exposure to organophosphorus pesticides. Hum Exp Toxicol. 1999; 18(1): 33-7. doi: 10.1177/096032719901800105.

27) Yavuz T, Delibas N, Yildirim B, Altuntas I, Candir O, Cora A, et al. Vascular wall damage in rats induced by organophosphorus insecticide methidathion. Toxicol Lett. 2005; 155(1): 59-64. doi: 10.1016/j.toxlet.2004.08.012.

28) Mattison DR, Thomford PJ. The mechanisms of action of reproductive toxicants. Toxicol Pathol. 1989; 17(2): 364-76. doi: 10.1177/019262338901700213.

29) Bonilla E, Hernandez F, Cortes L, Mendoza M, Mejia J, Carrillo E, et al. Effects of the insecticides malathion and diazinon on the early oogenesis in mice in vitro. Environ Toxicol. 2008; 23(2): 240-5. doi: 10.1002/tox.20332.

30) Lukaszewicz-Hussain A. Role of oxidative stress in organophosphate insecticide toxicity-Short review. Pestic Biochem Physiol. 2010; 98(2): 145-50. doi: 10.1016/j.pestbp.2010.07.006.

31) Sarabia L, Maurer I, Bustos-Obregon E. Melatonin prevents damage elicited by the organophosphorous pesticide diazinon on mouse sperm DNA. Ecotoxicol Environ Saf. 2009; 72(2): 663-8. doi: 10.1016/j.ecoenv.2008.04.023.

32) Jahromi VH, Koushkaki M, Kargar H. The effects of malathion insecticide on ovary in female rats. Natl park-Forsch Schweiz. 2012; 101(5): 231-5.

33) Koc ND, Kayhan FE, Sesal C, Muslu MN. Dose-dependent effects of endosulfan and malathion on adult Wistar albino rat ovaries. Pak J Biol Sci. 2009; 12(6): 498-503. doi: 10.3923/pjbs.2009.498.503. PMID: 19579998.

34) Ducolomb Y, Casas E, Valdez A, Gonzalez G, Altamirano-Lozano M, Betancourt M. In vitro effect of malathion and diazinon on oocytes fertilization and embryo development in porcine. Cell Biol Toxicol. 2009; 25(6): 623-33. doi: 10.1007/s10565-008-9117-3.

35) Oksay T, Naziroglu M, Ergun O, Dogan S, Ozatik O, Armagan A, et al. N-acetyl cysteine attenuates diazinon exposure-induced oxidative stress in rat testis. Andrologia. 2013; 45(3): 171-7. doi: 10.1111/j.1439-0272.2012.01329.x.

36) Sargazi Z, Nikravesh MR, Jalali M, Sadeghnia HR, Rahimi Anbarkeh F, Mohammadzadeh L. Diazinoninduced ovarian toxicity and protection by vitamins E. IJT. 2014; 8(26): 1130-5.

37) Ahmed RS, Seth V, Pasha ST, Banerjee BD. Influence of dietary ginger (Zingiber officinales Rosc) on oxidative stress induced by malathion in rats. Food Chem Toxicol. 2000; 38(5): 443-50. doi: 10.1016/S0278-6915(00)00019-3.

38) Babazadeh M, Najafi G. Effect of chlorpyrifos on sperm characteristics and testicular tissue changes in adult male rats. Vet Res Forum. 2017; 8(4): 319-26.

39) Edwards FL, Yedjou CG, Tchounwou PB. Involvement of oxidative stress in methyl parathion and parathion - induced toxicity and genotoxicity to human liver carcinoma (HepG2) cells. Environ Toxicol. 2013; 28(6): 342-8. doi: 10.1002/tox.20725.

40) Rahimi Anbarkeh F, Nikravesh MR, Jalali M, Sadeghnia HR, Sargazi Z, Mohammdzadeh L. Single dose effect of diazinon on biochemical parameters in testis tissue of adult rats and the protective effect of vitamin E. Iran J Reprod Med. 2014; 12(11): 731-6. PMID: 25709628, PMCID: PMC4336670.

41) Sutcu R, Altuntas I, Yildirim B, Karahan N, Demirin H, Delibas N. The effects of subchronic methidathion toxicity on rat liver: role of antioxidant vitamins $C$ and E. Cell Biol Toxicol. 2006; 22(3): 221-7. doi: 10.1007/s10565-006-0039-7.

42) Abbasnejad M, Jafari M, Asgari A, Hajihosseini R, Hajighalamali M, Salehi M, et al. Acute toxicity effect of diazinon on antioxidant system and lipid peroxidation in kidney tissues of rats. Daneshvar Medicine. 2009; 17(83): 35-42.

43) Akturk O, Demirin H, Sutcu R, Yilmaz N, Koylu H, Altuntas I. The effects of diazinon on lipid peroxidation and antioxidant enzymes in rat heart and ameliorating role of vitamin $\mathrm{E}$ and vitamin $\mathrm{C}$. Cell Biol Toxicol. 2006; 22(6): 455-61. doi: 10.1007/s10565-006-0138-5.

44) Sutcu R, Altuntas I, Buyukvanli B, Akturka O, Ozturka O, Koylu H, et al. The effects of diazinon on lipid peroxidation and antioxidant enzymes in rat erythrocytes: role of vitamins $\mathrm{E}$ and $\mathrm{C}$. Toxicol Ind Health. 2007; 23(1): 13-7. doi: 10.1177/0748233707076758.

45) Yilmaz N, Yilmaz M, Altuntas I. Diazinon-induced brain toxicity and protection by vitamins E plus C. Toxicol Ind Health. 2012; 28(1): 51-7. doi: 10.1177/0748233711404035.

46) Uzunhisarcikli M, Kalender Y. Protective effects of vitamins $C$ and $E$ against hepatotoxicity induced by methyl parathion in rats. Ecotoxicol Environ Saf. 2011; 74(7): 2112-8. doi: 10.1016/j.ecoenv.2011.07.001. 